JOURNAL OF MECHANICAL ENGINEERING, MANUFACTURES, MATERIALS AND ENERGY

\title{
Pengaruh Jarak Kaca Terhadap Efisiensi Alat Destilasi Air Laut yang Memanfaatkan Energi Matahari di Kota Medan
}

\section{Effect of Glass Distance on The Efficiency of Sea Water Distillation Tools That Utilize Solar Energy in The City of Medan}

\author{
C A Siregar1)*, Munawar A Siregar ${ }^{1}$, Sudirman Lubis ${ }^{1)}$ \\ 1) University Muhammadiyah of Sumatera Utara, Indonesia
}

*chandra@umsu.ac.id

\begin{abstract}
Abstrak
Pada saat ini, kondisi supplai air bersih di kota Medan ialah tidak lancar dan tidak merata di semua wilayah. Penangan masalah ini membutuhkan biaya yang cukup mahal dan tidak efektif. Alat destilasi surya tipe kolektor plat datar merupakan alat yang berfungsi sebagai pengubah air laut menjadi air tawar dengan energi matahari dan dapat dipergunakan untuk mengatasi masalah tersebut. Tujuan penelitian ini ialah mendapatkan variasi jarak kaca yang efektif pada alat destilasi air laut dengan memanfaatkan energi matahari menggunakan kolektor plat datar. Metode penelitian ini ialah dengan memodifikasi jarak kaca penutup untuk dapat memanfaatkan panas hasil kondensasi. Uap air yang dihasilkan diharapkan akan lebih banyak dengan menggunakan panas yang diperoleh tersebut. Jarak kaca penutup divariasikan dengan fiber hitam $15 \mathrm{~mm}, 25 \mathrm{~mm}$, dan $35 \mathrm{~mm}$, sehingga diharapkan dapat ditemukan jarak kaca penutup yang efektif, yang lebih banyak menghasilkan air tawar. Hasil dari penelitian diperoleh untuk jarak kaca penutup $15 \mathrm{~mm}, 25 \mathrm{~mm}$, dan $35 \mathrm{~mm}$ ini masing-masing mampu menghasilkan air tawar $450 \mathrm{ml}, 420 \mathrm{ml}$, dan $398 \mathrm{ml}$. Dari hasil ini bisa disimpulkan bahwa untuk jarak kaca penutup $15 \mathrm{~mm}$ mempunyai hasil lebih tinggi dibandingkan dengan jarak kaca penutup $25 \mathrm{~mm}$ dan $35 \mathrm{~mm}$.
\end{abstract}

Kata Kunci : Destilasi; Energi Matahari; Laju Perpindahan Panas

\begin{abstract}
At present, the condition of clean water supply in the city of Medan is unstable and uneven in all regions. Handling this problem requires quite expensive and ineffective costs. The solar distillation device from the type of flat plate collector is a device that functions as a converter of sea water into fresh water with the help of solar energy and can be used to overcome this problem. The purpose of this study is to obtain effective variations in glass distance on sea water distillation devices that utilize solar energy using flat plate collectors. The method of this research is to modify the distance of the cover glass to be able to utilize the heat from the condensation results. The water vapor produced is expected to be more by using the heat obtained. The distance of the cover glass is varied with $15 \mathrm{~mm}, 25 \mathrm{~mm}$ and $35 \mathrm{~mm}$ black fiber, so that it is expected to be able to find effective cover glass, which produces more fresh water. The results of the study were obtained for $15 \mathrm{~mm}, 25 \mathrm{~mm}$, and $35 \mathrm{~mm}$ cover glass distance, each capable of producing $450 \mathrm{ml}, 420$ $\mathrm{ml}$ and $398 \mathrm{ml}$ fresh water. From these results it can be concluded that the distance of the $15 \mathrm{~mm}$ cover glass gets more fresh water than the distance of the cover glass of $25 \mathrm{~mm}$ and $35 \mathrm{~mm}$.
\end{abstract}

Keywords: Distillation; Solar energy; Heat Transfer Rate

How to Cite: Siregar, C.A. 2018, Pengaruh Jarak Kaca Terhadap Efisiensi Alat Destilasi Air Laut yang Memanfaatkan Energi Matahari di Kota Medan, JMEMME, 2 (2): 51-55 


\section{C.A. Siregar, Pengaruh Jarak Kaca Terhadap Efisiensi Alat Destilasi Air Laut yang Memanfaatkan Energi Matahari di Kota Medan}

\section{PENDAHULUAN}

Kota Medan merupakan bahagian dari Negara Indonesia dengan iklim tropis, yang mendapat sinar atau radiasi matahari dengan intensitas cukup tinggi. Intensitas radiasi matahari yang sampai ke bumi dapat dimanfaatkan sebagai penyedia energi alternatif dan berkesinambungan (Siregar, 2016). Energi matahari dapat dimanfaatkan dengan cara konversi panas dan konversi pembangkit listrik tenaga surya (fotovoltaik). Sistem fotovoltaik hanya memiliki efisiensi sebesar $17 \%$ sedangkan konversi panas matahari dapat mencapai 70\% (Jaisankar, 2011).

Kondisi dilapangan yang terjadi saat ini adalah adalah tidak lancarnya air yang disalurkan oleh penyedia air bersih. Hal ini mengakibatkan warga sekitar menggunakan pompa listrik untuk menyedot air dari jaringan pipa-pipa penyedia air bersih. Perlakuan ini, membuat masyarakat harus mengeluarkan biaya listrik yang lebih besar.

Atas dasar itu, perlu sebuah inovasi terkait penyediaan air bersih yang bersumber dari air laut dan menggunakan energi matahari. Sistem ini disebut dengan Destilasi. Terdapat beberapa hal yang harus diperhatikan dalam menunjang kinerja alat destilasi. Salah satunya adalah kemiringan sudut karena akan mempengaruhi koefisien perpindahan panas rata-rata yang akan menurun seiring dengan meningkatnya sudut kemiringan. Fakta ini menunjukkan bahwa sudut kemiringan yang terlalu tinggi tida efektif untuk kolektor surya (Ambarita, 2017).

Destilasi air laut dengan memanfaatkan energi matahari sebagai sumber panas untuk menguapkan air laut. Butiran-butiran uap yang tercipta tersebut merupakan air tawar yang tidak berbau dan tidak memiliki rasa (Ward, 2003).

Dalam laporan ini hanya membahas pengaruh jarak kaca terhadap efisiesi kinerja dari alat destilasi dengan batasan masalah :

1. Pengujian dilakukan degan 3 (tiga) variasi jarak kaca dengan fiber hitam yakni pada jarak $15 \mathrm{~mm}, 25$ $\mathrm{mm}, 35 \mathrm{~mm}$.

2. Kemiringan sudut alat destilasi sebesar $40^{\circ} \mathrm{C}$.

3. Ukuran plat kolektor P x L ( 1,25m x $0,8 \mathrm{~m}$ ).

4. Kapasitas/Debet air laut yang digunakan sebanyak $3000 \mathrm{ml}$ dalam satu kali percobaan

5. Jenis kolektor yang digunakan adalah kolektor plat datar.

6. Kecepatan angin diabaikan.

7. Perhitungan dilakukan dengan asumsi destimasi langit cerah

8. Tidak menguji tingkat kejernihan air destilasi

Hasil perhitungan radiasi yang diterima dapat dicari dengan persamaan perpindahan panas radiasi (holman).

$$
Q=\sigma A\left(T_{1}^{4}-T_{2}^{4}\right)
$$

Adapun tujuan dari penelitian ini yakni untuk mendapatkan variasi jarak kaca yang efektif pada alat destilasi air laut dengan memanfaatkan energi matahari menggunakan kolektor plat datar.

\section{METODE PENELITIAN}

Peneltian ini dilakukan secara eksperimantal di Laboratorium Teknik Mesin, Fakultas Teknik, Universitas Muhammadiyah Sumatera Utara. Pengambilan data pada 24, 25 dan 26 Juni 
2015 pukul $11.00-14.00$ WIB. Jadwal penelitian ditampilkan pada tabel 1 .

Tabel 1. Jadwal Penelitian

\begin{tabular}{|c|c|c|c|c|c|c|c|c|}
\hline \multirow{2}{*}{ No } & \multirow{2}{*}{ Uraian } & \multicolumn{7}{|c|}{ Bulan ke } \\
\hline & & 1 & 2 & 3 & 4 & 5 & 6 & 7 \\
\hline 1 & $\begin{array}{l}\text { Kajian } \\
\text { Literatur }\end{array}$ & & & & & & & \\
\hline 2 & $\begin{array}{l}\text { Penyusunan } \\
\text { Proposal }\end{array}$ & & & & & & & \\
\hline 3 & $\begin{array}{l}\text { Pembuatan } \\
\text { Alat }\end{array}$ & & & & & & & \\
\hline 4 & $\begin{array}{l}\text { Rekayasa / } \\
\text { PengujianAlat } \\
\text { / Pengambilan } \\
\text { Data }\end{array}$ & & & & & & & \\
\hline 5 & $\begin{array}{l}\text { Penyusunan } \\
\text { Laporan }\end{array}$ & & & & & & & \\
\hline
\end{tabular}

Alat dan bahan penelitian yang digunakan, yakni:

1. Plat Absorber sebagai Sebagai komponen penyerap dan pemindah radiasi matahari yang tiba. Bahan ini harus memiliki daya serap panas yang baik dan daya pantul panas yang rendah. Bentuk plat absorber diperlihatkan pada gambar 1.

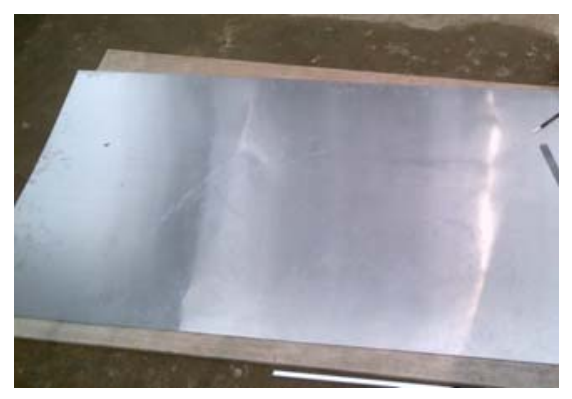

Gambar 1. Plat Absorber berbahan alumanium.

2. Fiber hitam digunakan sebagai wadah penjemur air laut. Penggunaan fiber ditujukan untuk menghindari korosi yang disebabkan oleh air laut, sedangkan pemilihan warna hitam bertujuan untuk meningkatkan kemampuan menyerap panas. Bentuk bahan ini diperlihatkan pada gambar 2 .

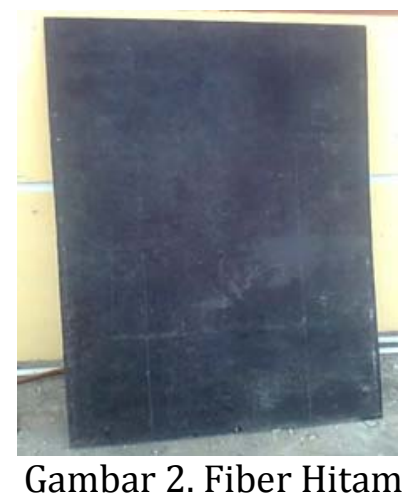

3. Asbes digunakan untuk meminimumkan kehilangan panas dari plat absorber. Bentuk bahan ini diperlihatkan pada gambar 3.

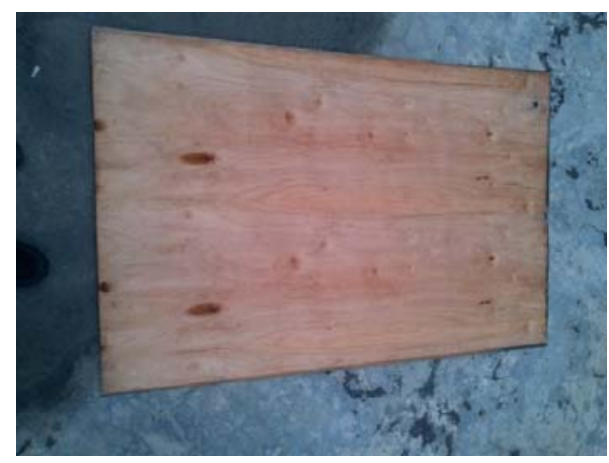

Gambar 3. Asbes

4. Kaca digunakan sebagai tutup atas. Berfungsi untuk meneruskan radiasi surya yang datang, menghambat perpindahan panas dari kolektor ke udara. Bentuk kaca yang dipergunakan dalam penelitian ini diperlihatkan pada gambar 4 . 


\section{C.A. Siregar, Pengaruh Jarak Kaca Terhadap Efisiensi Alat Destilasi Air Laut yang Memanfaatkan Energi Matahari di Kota Medan}

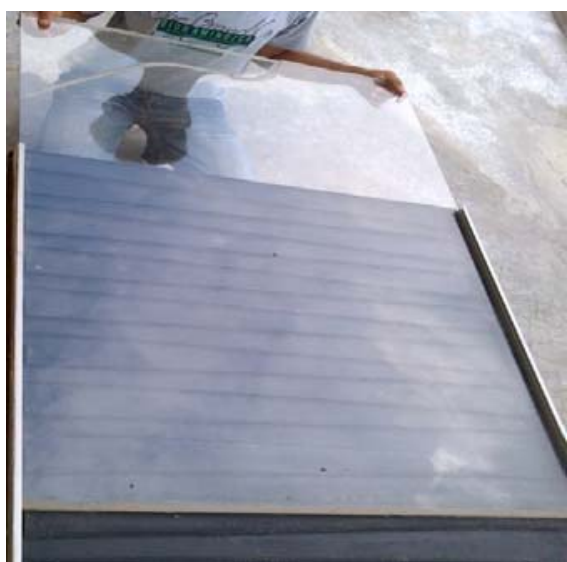

Gambar 4. Kaca penutup

5. Termokopel berfungsi untuk mengukur temperatur. Bentuk alat ini diperlihatkan pada gambar 5 .

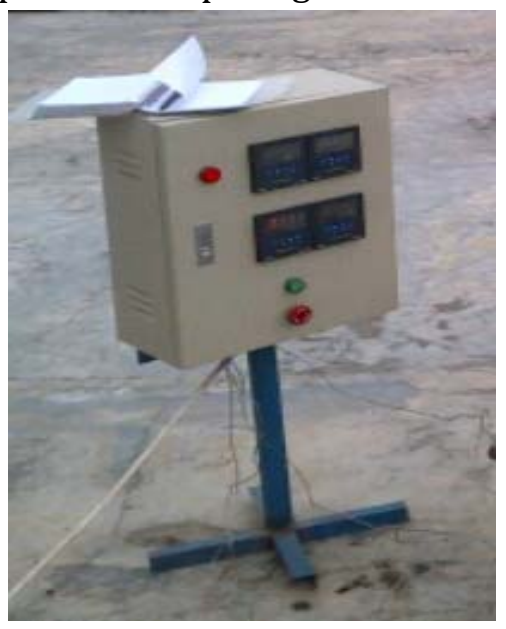

Gambar 5. Pembaca temperatur

Data temperatur dicatat per 60 menit sekali dengan penempatan sensor temperatur lingkungan $\mathrm{T}_{\mathrm{a}}\left({ }^{\circ} \mathrm{C}\right)$, temperatur permukaan kaca $\mathrm{T}_{\mathrm{g}}\left({ }^{\circ} \mathrm{C}\right)$, temperatur ruang basin $\mathrm{T}_{\mathrm{sv}}\left({ }^{\circ} \mathrm{C}\right)$ Temperatur air laut di ruang basin yang lebih tinggi $\mathrm{T}_{\mathrm{w} 1}\left({ }^{\circ} \mathrm{C}\right)$, Temperatur air laut di ruang basin yang lebih rendah ${ }_{\mathrm{Tw}}\left({ }^{\circ} \mathrm{C}\right)$. Desain alat destilasi air laut ditampilkan pada gambar 6 .

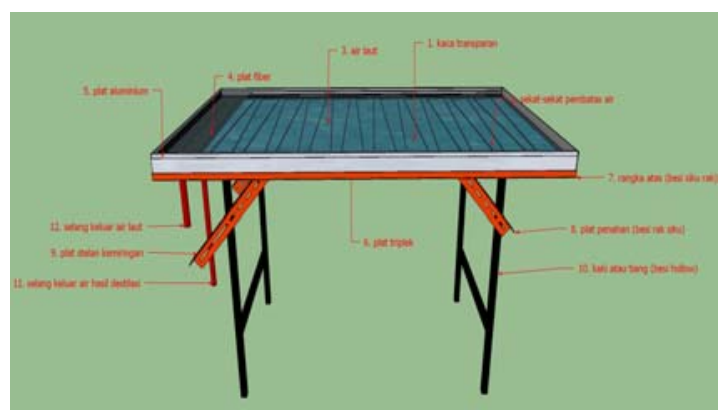

Gambar 6. Desain alat uji

Data temperatur digunakan untuk melakukan analisis berbagai paramater yang ingin diketahui. Setelah pengujian, dilakukan pengukuran volume terhadap air tawar yang dihasilkan.

\section{HASIL DAN PEMBAHASAN}

Hasil pengujian berupa butiran air yang terbentuk pada permukaan kaca diperlihatkan pada gambar 7. Hasil pengukuran temperatur yang dimulai pukul 10.00 wib - 14.00 wib ditampilkan pada tabel 2 .

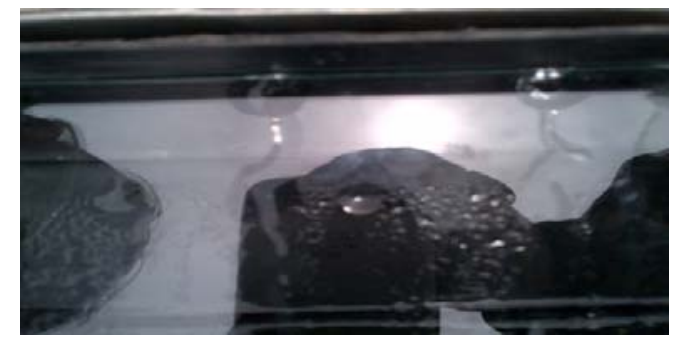

Gambar 7. Butiran - butiran air pada kaca

Hasil pengukuran diperoleh temperatur tertinggi pada pukul $13.00 \mathrm{wib}$ dengan jarak kaca $15 \mathrm{~mm}$. Hal ini disebabkan oleh luas ruang basin lebih kecil dibandingkan dengan jarak kaca 25 $\mathrm{mm}$ dan $35 \mathrm{~mm}$. Sehingga ruang basin dapat menyerap panas lebih maksimal.

Hasil perhitungan radiasi yang diterima pada pukul 13.00 wib diperoleh sebesar 149,21 watt untuk jarak kaca 15 
$\mathrm{mm}, 145,21$ watt (jarak kaca $25 \mathrm{~mm}$ ) dan 142,01 (jarak kaca 35 mm).

Tabel 2. Temperatur Maksimal pada Pukul 13.00 Wib

\begin{tabular}{|l|c|c|c|}
\hline \multirow{2}{*}{} & \multicolumn{3}{|c|}{ Jarak kaca } \\
\cline { 2 - 4 } & $15 \mathrm{~mm}$ & $25 \mathrm{~mm}$ & $35 \mathrm{~mm}$ \\
\hline $\mathrm{T}_{\mathrm{a}}\left({ }^{\circ} \mathrm{C}\right)$ & 35 & 35 & 35 \\
\hline $\mathrm{T}_{\mathrm{g}}\left({ }^{\circ} \mathrm{C}\right)$ & 55,4 & 54,5 & 54,5 \\
\hline $\mathrm{T}_{\mathrm{sv}}\left({ }^{\circ} \mathrm{C}\right)$ & 60,7 & 59,7 & 59 \\
\hline $\mathrm{T}_{\mathrm{w} 1}\left({ }^{\circ} \mathrm{C}\right)$ & 67,5 & 65,4 & 64,9 \\
\hline $\mathrm{T}_{\mathrm{w} 2}\left({ }^{\circ} \mathrm{C}\right)$ & 64,7 & 63,8 & 61,5 \\
\hline $\begin{array}{l}\text { T rata- } \\
\text { rata }\left({ }^{\circ} \mathrm{C}\right)\end{array}$ & 56,66 & 55,68 & 54,98 \\
\hline
\end{tabular}

Pada eksperimental yang dilakukan dengan kapasitas air laut $3000 \mathrm{ml}$, dengan waktu pengujian di mulai dari pukul 10.00 sampai dengan $14.00 \mathrm{Wib}$, diperoleh air tawar sebanyak $450 \mathrm{ml}$ dengan jarak kaca $15 \mathrm{~mm}, 420 \mathrm{ml}$ untuk jarak kaca $25 \mathrm{~mm}$ dan $398 \mathrm{ml}$ untuk jarak kaca $35 \mathrm{~mm}$. Hal ini menandakan bahwa semakin kecil jarak antara kaca penutup dengan fiber hitam maka alat destilasi akan bekerja secara lebih baik. Hal ini ditandai dengan temperatur pada ruang basin lebih tinggi pada jarak kaca $15 \mathrm{~mm}$ sehingga proses penguapan terjadi lebih cepat.

\section{SIMPULAN}

Dari hasil penelitian yang dilakukan diperoleh kesimpulan bahwa semakin kecil jarak antara kaca dengan fiber hitam maka semakin efektif kinerja alat destilasi air laut. Volume air tawar yang dihasilkan dengan jarak kaca $15 \mathrm{~mm}$ lebih banyak dari jarak $25 \mathrm{~mm}$ dan $35 \mathrm{~mm}$. Jarak kaca $15 \mathrm{~mm}$ menghasilkan air tawar sebanyak 450 . Selain itu, penyerapan radiasi matahari terbesar juga terdapat dengan jarak kaca $15 \mathrm{~mm}$.

\section{DAFTAR PUSTAKA}

Ambarita, Himsar., Siregar, $\mathrm{R}$ E T., Ronowikarto, A D., and Setyawan, E Y. 2017. Effects of the inclination angle on the performance of flat plate solar collector. IOP Publishing.

Holman, J.P. 1995. Perpindahan Kalor, Jakarta: Erlangga

Jaisankar, S., Ananth, J., Thulasi, S.. Jayasuthakar, S.T., and Sheeba, K.N. 2011. Comprehensive Review On Solar Water Heaters. Renewable and Sustainable Energy Reviews, Elsevier, 15, 3045-3050.

Siregar, C A., Ambarita Himsar., Ilmi Abdullah. 2016. Kajian Peleburan dan Pembekuan Material Berubah Phasa Pada Thermal Storage. Prosiding Science and Technology. Seminar Ilmiah Nasional Dies Natalis USU 64. Medan 18 - 19 Agustus 2016.

Ward Jhon. (2003), A Plastic Solar Water Purifier With High Output. Solar Energy Elsevier, 75, 433 - 437. 